\title{
Incidence of sarcoid-like reaction demonstrated on 18F-FDG PET-CT in head and neck cancer patients
}

\author{
LI Sonoda*, A Lakhani, S Ghosh-Ray \\ From International Cancer Imaging Society (ICIS) 14th Annual Teaching Course \\ Heidelberg, Germany. 9-11 October 2014
}

\begin{abstract}
Aim
Sarcoid-like reaction (SLR) is a well-known benign cause of nodal FDG-uptake in cancer patients and needs to be differentiated from active nodal metastatic disease. This study aimed to demonstrate the prevalence of sarcoidlike reaction in head and neck cancer (HNC) patients demonstrated on 18F-FDG-PET-CT.
\end{abstract}

\section{Methods}

A 6-year-period (2008-2013) retrospective analysis of 729 PET-CT scans (308 patients) of HNC was performed. Pre and post-treatment scans were compared and cases with persistent mediastinal/hilar nodal uptake despite therapeutic response elsewhere were further analysed and clinically followed up. Final diagnosis was reached by biopsy, clinical and imaging follow-up.

\section{Results}

SLR was diagnosed in $8 / 308(2.6 \%)$ HNC patients. Of which 3 had mediastinal nodal uptake only, 2 had bilateral hilar nodal uptake only and 3 had both mediastinal and hilar uptake. All the 8 patients had primary HNC and deep cervical lymphadenopathy but no distant metastases, hence misinterpretation of SLR would have upstaged as M1 (metastasis positive). 4 cases were identified on scan for restaging of suspected recurrence, and 4 were for primary tumour staging. The mean SUVmax of SLR was 6.9 (range 2.4-9.6), and the mean SLR nodal size was $1.6 \mathrm{~cm}$ in short axis (range $0.6-2.4 \mathrm{~cm}$ ), with no significant difference compared to active nodal diseases $(\mathrm{P}=0.33$ and 0.23$)$.

\section{Conclusion}

SLR was seen in $2.6 \%$ of HNC patients at 18 F-FDG PET-CT examinations. 18F-FDG PET-CT plays a significant role in the management of $\mathrm{HNC}$, and it is important to be aware of a possibility of SLR in order to avoid false-positive interpretation of metastasis.

Published: 9 October 2014

doi:10.1186/1470-7330-14-S1-P5

Cite this article as: Sonoda et al: Incidence of sarcoid-like reaction demonstrated on 18F-FDG PET-CT in head and neck cancer patients. Cancer Imaging 2014 14(Suppl 1):P5.

\footnotetext{
* Correspondence: luke@sonoda.co.uk

Paul Strickland Scanner Centre, Mount Vernon Hospital, London, UK
}

Submit your next manuscript to BioMed Central and take full advantage of:

- Convenient online submission

- Thorough peer review

- No space constraints or color figure charges

- Immediate publication on acceptance

- Inclusion in PubMed, CAS, Scopus and Google Scholar

- Research which is freely available for redistribution 